\title{
NATURALIZAÇÃO DA VIDA: UMA CRÍTICA AO ESFORÇO EM NATURALIZAR A INFÂNCIA E A MUSICALIDADE DAS CRIANÇAS
}

\author{
Andréia Pereira de Araújo Martinez $z^{1}$ (1)
}

RESUMO: A infância é uma etapa da vida humana caracterizada, por alguns ideários sociais, como algo natural. De modo semelhante, a criança e o desenvolvimento de sua musicalidade transitam em meio a essas percepçóes, em que ocorre um esforço de naturalização da atividade humana. Este artigo parte de uma pesquisa de doutorado e aborda tal questão tendo a perspectiva histórico-cultural como pressuposto teórico, lançando um olhar reflexivo e questionador para esse fenômeno, preconizando que a existência humana extrapola as determinaçôes naturais, pois é engendrada pelas relações sociais e culturais, historicamente constituídas.

Palavras-chave: Infância. Criança. Musicalidade. Naturalização da vida. Atividade humana.

\section{Naturalization of life: a critique of the effort to naturalize children and the musicality of children}

ABSTRACT: Childhood is a stage of human life that, among some social ideals, is characterized as something natural. In a similar way, the child and the development of his musicality pass through these perceptions, in which there is an effort to

${ }^{1}$ Universidade de Brasília - Brasília (DF), Brasil. E-mail: andreiamartinez4@gmail.com DOI: $10.1590 / C C 0101-32622019213298$ 
naturalize human activity. This article starts from a doctoral research and approaches this question taking the culturalhistorical perspective as a theoretical presupposition, throwing a reflective and questioning look at this phenomenon, suggesting that human existence extrapolates natural determinations because it is engendered by social and cultural relations, historically constituted.

Keywords: Childhood. Child. Musicality. Naturalization of life. Human activity.

\section{INTRODUÇÃO}

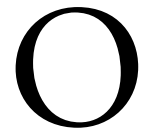

$s$ estudos e as discussóes sobre a infância trazem diferentes e contraditórias formas de entendimento sobre essa fase da vida. Uma dessas linhas de pensamento esforça-se em denominar a infância como algo natural e universal. Tal postura tende a ignorar as diversas infâncias existentes e descaracteriza a constituição humana como algo que emerge das relaçóes sociais e que sofre transformações ao longo da história.

Esse movimento também é perceptível em relação às crianças e ao desenvolvimento de sua musicalidade. A criança é percebida como um ser incapaz que precisa ser preparada para viver o amanhá, o futuro, negando, assim, sua existência no presente e suas inúmeras possibilidades de viver ativamente, sendo um ser que sofre transformaçóes e, dialeticamente, transforma o meio à sua volta. De modo semelhante, a musicalidade é permeada pelos esforços de naturalizaçấo da atividade humana. Dom, missão, vocação, talento, são palavras que transitam entre esses discursos que evidenciam tal esforço, o que contribui para uma percepção naturalizada da existência do ser humano e, além disso, acarreta em visōes preconceituosas em relação às infâncias, às crianças e suas possibilidades musicais.

Esse modo de conceber delineia o esforço em transformar a atividade humana em algo natural, influenciando os modos de senti-la, pensá-la e avaliá-la, resultando na criação de valores naturalistas, 
que desconsidera o contexto histórico e os movimentos culturais que impulsionam as condições de existência humana.

Pode-se pensar que o esforço de naturalização da vida seja simplório, porém é algo que pode sentenciar profundas influências nos modos de agir e perceber a sociedade, bem como a própria atividade humana, ao influenciar a formação do pensamento social. As ideias e os pensamentos são representaçóes que se formam dialogicamente nas relaçôes sociais existentes no mundo (JOVCHELOVITCH, 2008). Freire (1996) alerta-nos que o esforço de naturalização da vida humana se funda em uma estratégia que recorrentemente é evidenciada, tornando-se eficaz para a perpetuação de situaçóes opressivas e de acobertamento da realidade.

Marx (2013) elucida que é preciso desconfiar e questionar os movimentos de naturalização da vida humana, pois esta se constitui em um processo dialético de constantes mudanças e transformaçôes. Ou seja, se existe uma tendência de naturalizar a vida, isso corrobora para que essas mudanças e transformaçóes fiquem estagnadas. $\mathrm{O}$ autor elucida que é necessário transpor a aparência e buscar a essência, examinando cautelosamente o que se apresenta como algo natural, pois nada é impossível de sofrer transformaçóes, sobretudo quando tratamos do processo de desenvolvimento do ser humano. Segundo Vigotski (2012c), o ser humano é um ser de possibilidades, capaz de se desenvolver nas mais diversas áreas do conhecimento e de múltiplas formas.

Este artigo emerge da pesquisa de doutorado que tem por foco as crianças, os bebês e as diversas infâncias existentes, defendendo a tese de que a musicalidade das crianças é uma atividade humana que se desenvolve em meio à cultura, que ocorre na mais tenra infância, quando ainda se é um bebê. Tal pesquisa se consolida na perspectiva históricocultural de Vigotski.

O movimento de naturalização da vida é fundamentalmente metafísico, provocando explicaçóes da realidade a partir de uma tradução natural dos fatos e acontecimentos, que a tomam como natural em vez de considerá-la resultado de processos constituídos social e historicamente. Na mais tenra idade, as crianças e sua musicalidade desenvolvem-se em meio às relaçóes e às experiências sociais, culturais e 
históricas. A naturalização implica que os bebês e as crianças pequenas bem como sua musicalidade são produtos naturais e, assim, que as práticas educativas pouco interferem. O que equivale a anunciar que alguns poucos seres escolhidos "ao acaso" têm o dom e o talento para a atividade musical (PEDERIVA; TUNES, 2013), enaltecendo "crianças prodígios" envolvidas pelo "manto sagrado" de sua "natureza excepcional".

Pederiva e Tunes (2013) denunciam o pensamento de cunho inatista que dá vazấo ao dom e ao talento inato, descaracterizando a musicalidade humana. Esta é compreendida, em alguns contextos sociais, como um comportamento que se limita à dimensáo biológica e pertencente a poucos, o que fortalece a propagaçáo da ideologia do dom, do talento, provocando, assim, o preconceito entre as diferentes possibilidades humanas e também a ideia de uma educação que limita o desenvolvimento musical, já na primeira infância, deixando marcas desse rótulo por toda a vida.

Tal modo de perceber os seres humanos e suas atividades pode suscitar desigualdades impostas por padróes preestabelecidos socialmente, bem como uma prática educativa diferenciada - em que um determinado grupo de crianças recebe investimentos para atividades diversificadas, entre elas a musical, e para os demais grupos isso é considerado desnecessário. Essa visão naturalista da existência humana acaba provocando modos de estruturaçáo do pensamento social e também do próprio investimento na educação e nas políticas públicas.

Vigotski (2009) esclarece que o ser humano se desenvolve a partir de suas experiências vivenciadas e internalizadas. Tais experiências são armazenadas no cérebro e, posteriormente, podem ser reproduzidas ou transformadas, dando vazão ao ato imaginativo e criativo da atividade humana.

O cérebro não é apenas o órgão que conserva e reproduz nossa experiência anterior, mas também, o que combina e reelabora, de forma criadora, elementos da experiência anterior, erigindo novas situaçóes e novo comportamento (VIGOTSKI, 2009, p. 14). 
Portanto, o desenvolvimento da musicalidade das crianças se dá a partir da diversidade de experiências que são oportunizadas e as práticas educativas podem contribuir nesse processo.

Nesse sentido, este artigo intenta problematizar as discussões que permeiam a percepção de criança, suas infâncias e suas possibilidades de desenvolvimento musical. Aborda a desnaturalização do comportamento humano, evidenciando a atividade musical como uma constituição pertencente à existência humana em meio à cultura, com base nas experiências, na imaginação e na criação (VIGOTSKI, 2009), o que desencadeia uma reflexão acerca das práticas educativas de atividade musical voltadas para as crianças e as infâncias na educação básica.

\section{INFÂNCIAS, CRIANÇAS E SUA MUSICALIDADE}

Ariès (1981) discorre que, até o século XII, a duração da infância era bastante reduzida, compreendendo os primeiros anos de vida em que a criança necessitava dos cuidados dos adultos ou de crianças maiores. Logo que conseguia certa independência, já era compreendida como um ser capaz de viver em meio aos adultos e compartilhar das mais diversas atividades. Por volta do século XVII, começa a surgir o sentimento de infância semelhante ao existente nos dias atuais, em que tal período se prolonga por mais tempo e a criança, de certa forma, é mais preservada da vida adulta. Assim, o lugar e o papel da criança na sociedade mudam, bem como a estrutura das práticas educativas que são voltadas a ela. Essa concepção foi ilustrada pelo autor a partir de dados catalogados da sociedade europeia, o que ocasionou algumas críticas em relação a sua pesquisa, sendo considerada eurocêntrica, uma vez que não situa essa construção no continente como um recorte de análise, mas trata como se as infâncias se desenvolvessem de forma universal, independentemente de sua territorialidade, entre outros aspectos.

Já Elkonin (2009) partiu de uma abordagem metodológica diferenciada, utilizando, para análise, a divisão social do trabalho em seus estudos acerca do desenvolvimento da brincadeira na sociedade, 
o que o permitiu argumentar que a criança e a infância se constituem historicamente em meio às relaçóes culturais. $\mathrm{O}$ autor esclarece que a divisão social do trabalho ocasionou uma ruptura em relação ao papel da criança na sociedade, pois provocou o seu afastamento do processo de produção. Antes, as crianças de pouca idade participavam das mesmas atividades que os adultos e utilizando as mesmas ferramentas. Com a complexificação das ferramentas de trabalho, aos poucos, as crianças se distanciaram das atividades laborais. Vale ressaltar que tal organização ainda pode ser encontrada em alguns grupos sociais. $\mathrm{O}$ autor tem por base o pensamento marxista: o ser humano se constitui por meio do trabalho, da ferramenta e do signo.

A infância não se limita a uma fase estanque e determinada da vida, pois se constitui em movimento dialético em meio ao contexto cultural e às atividades humanas compartilhadas nos grupos sociais. A infância não é sempre a mesma, ela se forma em constante processo de transformação, de múltiplas maneiras e formatos.

Portanto, para o ser humano se desenvolver é preciso nascer e crescer entre os humanos, compartilhar de uma vida social e cultural, vivenciar e trocar experiências. É preciso aprender em meio às relaçóes sociais e internalizar os conhecimentos produzidos ao longo da história, por meio de práticas educativas que podem ocorrer nos mais diversos contextos.

Nesse sentido, a musicalidade humana não é um atributo natural destinado a poucos eleitos, mas emerge da necessidade do ser humano de perceber os sons existentes em seu próprio corpo e ao seu redor. A necessidade de perceber as sonoridades está para além da matéria, pois lida com as emoçóes ao provocar sentimentos que são desencadeados a partir da organização dos sons, dão vazão à diversidade de expressóes musicais existentes, emergem das experiências culturais e sintetizam as experiências vivenciadas a cada contexto social e histórico.

Com base no materialismo histórico-dialético, Vigotski (2012a; 2012b) discute que o processo de desenvolvimento humano surge em meio às inadaptaçóes que emergem dos desafios impostos pelo meio, provocando novas aspiraçóes, atraçóes e interesses, que se 
constituem em forças motrizes do comportamento e impulsionam o desenvolvimento humano. Portanto, não se trata apenas de uma questão natural. O ser humano, além de se constituir de uma base biológica, desenvolve-se em meio às experiências e às atividades culturais, possibilitando a consciência de si e do meio social, de forma dialética e compondo uma unidade. Nesse movimento, o ser humano se depara com as inadaptaçóes da vida que o impulsiona a se movimentar, a agir, a mudar e se transformar. Surgem novas percepçóes e novos modos de ser e estar no mundo.

\section{MUSICALIDADE HUMANA QUE EMERGE NA MAIS TENRA INFÂNCIA}

Este artigo traz uma discussão acerca do esforço de naturalização da atividade musical a partir de uma pesquisa que se propôs a examinar as primeiras manifestaçóes sonoro-musicais dos bebês — a percepção dos sons, a escuta, a experimentação sonora, a troca de experiências com as outras crianças e com os adultos, entre outras possibilidades de experiências sonoro-musicais. Por meio da observação, na imersão do olhar no comportamento musical dos bebês, buscou-se compreender a essência, sua função e estrutura diante do desenvolvimento da musicalidade humana. A pesquisa se deu ao longo do ano de 2017, acompanhando o desenvolvimento musical de bebês, em uma turma de creche, em uma escola conveniada da rede pública de ensino do município de Alto Paraíso, no Estado de Goiás (MARTINEZ, 2017).

As observaçóes foram convertidas em narrativas e este artigo ilustra duas delas na intenção de provocar uma reflexão acerca do comportamento musical dos bebês, debatendo que tal processo se constitui em meio às relações sociais, culturais e históricas.

\section{PRIMEIRA NARRATIVA: OLHA O CHORO}

A sala cheia de brinquedos. Tem brinquedo na estante e no tapete. Os bebês estão em volta dos brinquedos. Eles pegam os brinquedos e brincam. 
Lays (oito meses de idade) demonstra que não quer brincar e faz movimentos com o corpo indicando que quer colo. Ela olh a para a professora e se movimenta, como a professora não faz nada, ela começa a chorar. O choro só para quando ela consegue o que quer - o colo da professora.

\section{SEGUNDA NARRATIVA: CHOCALHO, TAMBOR E CANTORIA}

Lays (oito meses de idade) está no tapete emborrachado rodeada de brinquedos sonoros. Ela balança o chocalho, ele emite som. Balança para ambos os lados, rápido e devagar. Produz um ritmo manuseando o chocalho. Logo, Lays descobre outro brinquedo sonoro. Ela bate no tambor. E, também, experimenta a batida rápida e lenta, elaborando um ritmo. Para acompanhar esses sons, Lays começa a cantar. Cantarola do seu jeito, misturando balbucios e vocalizaçôes.

A expressão sonora por meio do choro, também compreendida como a gênese da expressão da musicalidade, indica, nos primeiros meses de vida do bebê, uma função notadamente orgânica, que se manifesta de forma espontânea como um modo de descarga de tensão em meio aos estados de desconforto fisiológico, que pode surgir motivado por várias causas: fome, irritação da pele em contato com a urina ou fezes, dor, frio, entre outras. $\mathrm{O}$ choro, que no primeiro momento de contato com a vida extrauterina era um reflexo da laringe, torna-se, aos poucos, um modo de o bebê expressar que algo não está bem, que algo o está incomodando; e quanto maior o envolvimento com o outro da relação social, mais facilmente essa pessoa pode auxiliar a aliviar o desconforto do bebê.

Com o passar das primeiras semanas, a função do choro do bebê se transforma, deixa de ter um caráter essencialmente biológico, deixa de ser um ato reflexo de suas necessidades vitais, assumindo novas funçóes e, assim, começa a expressar novas necessidades, como, por exemplo, a presença do outro da relação social. Os bebês começam a elaborar seu comportamento sonoro para chamar a atenção para sua necessidade do convívio social, já indicando as primícias de sua atividade cultural. 
O que é fácil de observar é que, no início, o choro é uma reação do tipo compulsivo que só para quando é eliminada a causa física que o provocou. Mais tarde, porém, ele se torna uma representação, algo próximo da teatralidade. O choro torna-se uma reação, por vezes, difícil de interpretar, da criança ao meio social, não ao meio natural. $\mathrm{O}$ que evidencia a existência na criança de mecanismos de controle que lhe permitem chorar ou parar de chorar em função de objetivos que não são mais determinados pela ordem biológica (PINO, 2005, p. 205, grifo do original).

O choro como "representação" ou como "teatralidade", como expressa o autor, é o que se evidencia na primeira narrativa - Lays chora. Mas ela não chora porque está incomodada por estar suja, por estar com fome, por sentir dor, ou alguma sensação dessa natureza. Na realidade, Lays chora para chamar a atenção do outro da relação social, que, no caso, é a professora. Chora para solicitar a presença do outro e para solicitar um aconchego, um colo. Lays se utiliza da expressáo do choro como uma forma de comunicação elementar com o outro da relação social. "É sabido que a forma mais primitiva da fala é o grito e outras reaçóes vocais que acompanham movimentos, fortes emoçóes e assim por diante" (VIGOTSKI; LURIA, 1996, p. 208). A expressão do choro muda de função, passa a receber um atributo de expressão comunicativa. Nesse caso, o papel do outro da relação social também é essencial. É importante que o outro tenha condiçóes para discernir o que os bebês desejam comunicar com seus choros, pois é a partir desse reconhecimento que essa expressão sonora começa a significar, podendo também ser compreendida como um comportamento sonoro-musical.

Uma criança de menos de um ano de idade representa um ser mudo (no sentido exato da palavra). É bem verdade que se pode observar muitos fenômenos vocais na criança [...]. Qualquer um que lide com crianças está familiarizado com o estalar de lábios, com os gemidos ou com a série de sons inarticulados impossíveis de reproduzir nestas páginas (VIGOTSKI; LURIA, 1996, p. 209). 
Os sons surgem na tentativa de se comunicar com o outro da relação social, como expressão de estados afetivos e, assim, como uma forma de elaboração do comportamento sonoro-musical. Surgem os balbucios e as vocalizaçôes. Nesse sentido, a forma de expressão sonora essencialmente biológica sofre uma revolução dialética, transformando-se, qualitativamente, em formas de expressóes sonoro-musicais regidas pela ação da cultura, nos mais diferentes contextos sociais da existência humana e, aos poucos, vai se transformando, consolidando novas formas de expressão da musicalidade. Além de tentar se comunicar com o outro da relação social, de solicitar sua presença, os bebês começam a perceber o contexto social e as formas de atuação cultural entre os seres humanos. Começam a perceber as atividades culturais que permeiam a vida humana. A atividade musical é uma delas. Os bebês ouvem as vozes e os cantos entoados pelas pessoas de seu convívio social, internalizam o que vivenciam e, logo, tentam imitar e também começam a elaborar seu próprio comportamento sonoro-musical. Aos poucos, a partir do momento em que conseguem desenvolver certo domínio do próprio corpo, os bebês começam a imitar e a experimentar suas possibilidades de expressão sonora. A boca, os lábios e a língua são partes do corpo muito experimentadas na tentativa de expressar e criar sonoridades, tais como balbucios, estalos, tremores, sons de beijo, vocalizaçóes, enriquecendo, assim, seu repertório de expressões da musicalidade.

$\mathrm{Na}$ segunda narrativa percebemos que Lays experimenta as possibilidades sonoras dos brinquedos existentes na creche. Mas ela não faz só isso. Ela acompanha os sons dos instrumentos musicais, do chocalho e do tambor. Ela emite balbucios, vocalizaçóes, cantarola e começa a imitar sons diversos, como uma tentativa de imitar vozes e realizar cantos, mesmo ainda não tendo a fala humana constituída. Prestes (2014, p. 345) elucida que "a primeira coisa é pensar que a fala não começa quando a criança pronuncia a primeira palavra, a fala começa muito antes disto: quando a criança ouve a gente falar com ela”. De forma semelhante, a expressão da musicalidade não começa quando a criança começa a cantar; inicia-se muito antes disso, desde quando o bebê teve o primeiro contato com as vozes e os cantos entoados pelos 
humanos. Ou seja, esse processo de brincar com a voz e os cantos tem início muito antes de a fala humana estar consolidada, pois principia quando o bebê começa a ouvir o mundo sonoro-musical humano e a emitir os primeiros sons. Não é uma ação que acontece de modo natural, mas que emerge das relações sociais.

Aos poucos, por meio da realidade concreta, Lays começa a tomar consciência do universo sonoro-musical e também começa a regular seu comportamento expressivo-musical. Lays inicia esse processo tomando por base as experiências sonoro-musicais anteriores que vivenciou e internalizou, tais como as conversas, os cantos e os acalantos, experiências que se dão na vida. Tudo isso se constitui em material sonoro-musical que o bebê internaliza e, assim, começa a utilizar, elaborando seu próprio comportamento musical.

\section{BREVES CONSIDERAÇÕES}

A naturalização da musicalidade humana tem um vínculo forte com as percepçóes de preconceito em relaçáo ao que o outro é capaz de fazer, criando barreiras acerca do fazer musical das pessoas, em que são preestabelecidos padróes reconhecidos socialmente e que estabelecem um modelo a ser seguido. Esse modo de naturalização da vida apoia-se em uma visão limitadora, estabelecendo um projeto de naturalização ao impor uma interpretação que determina a existência humana ao mundo da natureza, desconsiderando o processo histórico e cultural engendrado pelos humanos.

Nesse sentido, os bebês e as crianças pequenas não são considerados como capazes de desenvolver sua musicalidade, pois não se enquadram nos moldes estabelecidos como padróes musicais. Eles ainda não têm um corpo apropriado e não alcançaram idade suficiente para se aventurarem no mundo sonoro-musical.

Tais percepções se estabelecem em um critério metafísico ao lançar um modelo que deve ser seguido de modo homogêneo, desconsiderando as especificidades humanas, o que acaba provocando distinçóes na concretude da existência humana. Cria-se um pensa- 
mento, uma ideia, uma visão, que se concretiza na materialização de uma sentença para alguns seres que não se enquadram nos padróes estabelecidos. Trata-se de um critério metafísico de naturalização da vida humana.

Contrariamente ao esforço de naturalização da atividade humana, podem ser verificadas, por meio das observaçóes expressas pelas narrativas, as inúmeras possibilidades do comportamento sonoro-musical manifestado pelas crianças na mais tenra idade.

Os bebês já nascem providos de um aparato biológico que os permite desenvolver sua musicalidade, mas é no contato com a cultura que esse comportamento musical humano se consolida e se desenvolve. Os bebês começam a brincar com os sons produzindo balbucios, tremores, estalos e vocalizaçóes. Os bebês ouvem vozes e cantos. Essas experiências sonoro-musicais são internalizadas pelos bebês e eles começam a imitar o que ouvem, experimentando novas expressóes sonoro-musicais. Assim, começam a elaborar seu comportamento sonoro-musical em meio à cultura, vivenciando sua musicalidade.

O comportamento musical se desenvolve sob a ação da cultura entre as relaçóes sociais. Conversas, cantos e acalantos são entoados para os bebês. Durante a troca de fraldas, o banho, a amamentação, e em vários outros momentos, existe esse envolvimento com as práticas culturais. Essas experiências sonoro-musicais compartilhadas são internalizadas pelos bebês. Eles absorvem as formas sociais de conduta relacionadas à expressão da musicalidade essencialmente humana. Experimentam as possibilidades expressivo-musicais do próprio corpo. Os bebês ouvem, observam e sentem. Vivenciam e internalizam a experiência. Criam e empregam novas sonoridades. Regulam seu comportamento musical. Com o passar do tempo, começam a imitar o que viram e ouviram. Começam a criar e a empregar ativamente sons com a boca, tremores e estalos com os lábios e a língua, a cantarolar, elaborando e emitindo sons vocais, indicando, assim, o desenvolvimento de sua musicalidade (que não se limita a um processo natural). 
Portanto, pensando nos efeitos das relaçóes sociais e das experiências sonoro-musicais vivenciadas para o desenvolvimento da musicalidade, é admissível enfatizar a importância de práticas educativas que se constituam considerando as especificidades das crianças como seres capazes e atuantes na sociedade, respeitando suas infâncias e oportunizando uma variedade de atividades musicais.

\section{REFERÊNCIAS}

ARIÈS, P. História social da criança e da família. 2. ed. Rio de Janeiro: Guanabara, 1981.

ELKONIN, D.B. Psicologia do jogo. São Paulo: WMF Martins Fontes, 2009.

FREIRE, P. Pedagogia da autonomia. 36. ed. São Paulo: Paz e Terra, 1996.

JOVCHELOVITCH, S. Os contextos do saber: representações, comunidade e cultura. Petrópolis: Vozes, 2008.

MARTINEZ, A.P. de A. Infâncias musicais: o desenvolvimento da musicalidade dos bebês. 307 f. Tese (Doutorado) - Programa de Pós-Graduação em Educação, Faculdade de Educação, Universidade de Brasília, Brasília, 2017.

MARX, K. O capital: crítica da economia política. Livro 1: O processo de produção do capital. São Paulo: Boitempo, 2013.

PEDERIVA, P.L.M.; TUNES, E. Da atividade musical e sua expressão psicológica. Curitiba: Prismas/Appris, 2013.

PINO, A. As marcas do humano: às origens da constituição cultural da criança na perspectiva de Lev S. Vigotski. São Paulo: Cortez, 2005.

PRESTES, Z. Entrevista. Zero a Seis, Florianópolis, v. 16, n. 30, p. 340-352, jul./dez. 2014.

VIGOTSKI, L.S. Imaginação e criação na infância. São Paulo: Ática, 2009.

Obras Escogidas III: Problemas del desarrollo de la psique. Madri: Machado Libros, 2012a.

- Obras Escogidas IV: Paidología del adolescente/Problemas de la psicologia infantil. Madri: Machado Libros, 2012b. 
- Obras Escogidas V: Fundamentos de defectología. Madri: Machado Libros, 2012c.

VIGOTSKI, L.S; LURIA, A.R. Estudos sobre a história do comportamento: o macaco, o primitivo e a criança. Porto Alegre: Artes Médicas, 1996.

Recebido em 24 de agosto de 2018.

Aprovado em 11 dezembro de 2018. 